\title{
Solvation Structure Determination of Nickel(II) Ion in Six Nitriles Using Extended X-Ray Absorption Fine Structure Spectroscopy
}

\author{
Yasuhiro INADA and Shigenobu FunAHASHI \\ Laboratory of Analytical Chemistry, Faculty of Sciences, Nagoya University, \\ Chikusa, Nagoya 464-01, Japan
}

\begin{abstract}
The solvation structures of the nickel(II) ion in six nitriles have been determined using X-ray absorption fine structure spectroscopy. The coordination number and the $\mathrm{Ni}-\mathrm{N}$ bond length are 6 and $206.9 \pm 0.6 \mathrm{pm}$ in acetonitrile, $5.9 \pm 0.2$ and $206.9 \pm 0.6 \mathrm{pm}$ in propionitrile, $6.0 \pm 0.2$ and $206.8 \pm 0.6 \mathrm{pm}$ in butyronitrile, $6.0 \pm 0.2$ and $206.8 \pm 0.6 \mathrm{pm}$ in isobutylonitrile, $6.0 \pm 0.2$ and $206.8 \pm 0.6 \mathrm{pm}$ in valeronitrile, and $6.0 \pm 0.2$ and $206.5 \pm 0.7 \mathrm{pm}$ in benzonitrile, respectively. The structure parameters around the nickel(II) ion in all the nitriles are not affected by the bulkiness of the nitrile molecules. On the basis of the obtained structure parameters, we have discussed the structural characteristics around the nickel(II) ion with nitrogen and oxygen donor solvents and the reaction mechanisms for nitrile exchange on the nickel(II) ion.
\end{abstract}

Keywords Solvation structure, nickel(II) ion, nitrile, bulkiness

Metal ions in coordinating solvents are coordinated by several solvent molecules. The knowledge of the solvation structure around the metal ion is indispensable for the clarification of reactivities of the metal ion in solution because such reactivities must be directly affected by the structure around the metal ion in its ground state. The hydration structures of many metal ions have been evaluated using X-ray and neutron diffraction methods and extended X-ray absorption fine structure (EXAFS) spectroscopy. ${ }^{1}$ The hydration structure of the first-row transition metal(II) ions is 6coordinate octahedral. Recently, the studies of the solvation structure of the first-row transition metal(II) ions in some non-aqueous solvents have pointed out that the bulkiness of solvent molecules can reduce the solvation number of a metal(II) ion in some instances, due to the large steric repulsion between the bound solvent molecules in the first coordination sphere. ${ }^{2-9}$ For example, the coordination number of $\mathrm{Mn}$ (II), $\mathrm{Fe}(\mathrm{II})$, and $\mathrm{Ni}(\mathrm{II})$ ions is 5 and that of $\mathrm{Co}(\mathrm{II}), \mathrm{Cu}(\mathrm{II})$, and $\mathrm{Zn}$ (II) ions is 4 in a bulky solvent of 1,1,3,3-tetramethylurea (TMU). ${ }^{2}$ A similar characteristic is also observed in the bulkier hexamethylphosphoric triamide (HMPA) solvent. ${ }^{3}$

It should be noted that the molar volume of a solvent is not a measure of the bulkiness of coordinated solvent molecules. The results of the solvation structure of the Mn(II) ion in several nitriles have indicated that the difference in an alkyl substituent of the cyano group does not affect the solvation structure of the Mn(II) ion. ${ }^{4}$ In the case of these nitriles, because the substituent of a cyano group is radially expanded from the $\mathrm{Mn}$ (II) center, the interligand steric repulsion is not very effective. However, the bulkiness of solvent molecules is more effective for the metal ion with a smaller ionic radius, as expected from the change in solvation number for a series of metal(II) ions in TMU. Even in the bulkier HMPA, the $\mathrm{Mn}$ (II) ion has the solvation number of 5 because of its relatively large ionic radius $(83 \mathrm{pm}$ in the high-spin octahedron $)^{10}$, whereas smaller metal(II) ions have a 4coordinate tetrahedral structure. In this study, we have determined the structure parameters around the Ni(II) ion in six nitriles with different alkyl substituents for the cyano group: acetonitrile $\left(\mathrm{CH}_{3} \mathrm{CN}, \mathrm{AN}\right)$, propionitrile $\left(\mathrm{CH}_{3} \mathrm{CH}_{2} \mathrm{CN}, \mathrm{PN}\right)$, butyronitrile $\left(\mathrm{CH}_{3} \mathrm{CH}_{2} \mathrm{CH}_{2} \mathrm{CN}, \mathrm{BuN}\right)$, isobutyronitrile $\left(\left(\mathrm{CH}_{3}\right)_{2} \mathrm{CHCN}, \mathrm{iBuN}\right)$, valeronitrile $\left(\mathrm{CH}_{3} \mathrm{CH}_{2} \mathrm{CH}_{2} \mathrm{CH}_{2} \mathrm{CN}, \mathrm{VN}\right)$, and benzonitrile $\left(\mathrm{C}_{6} \mathrm{H}_{5} \mathrm{CN}\right.$, BzN) using EXAFS spectroscopy. As the ionic radius of the $\mathrm{Ni}(\mathrm{II})$ ion (69 pm in octahedron) is smaller than the Mn(II) ion ${ }^{10}$, it is important to determine the solvation structure for the smaller $\mathrm{Ni}$ (II) ion. On the basis of the obtained structure parameters in nitriles, we discuss the structural character of the solvated $\mathrm{Ni}(\mathrm{II})$ ion with nitrogen as a donor atom by comparison with the corresponding results in solvents with an oxygen donor atom. We also discuss the reaction mechanisms for nitrile exchange on the $\mathrm{Ni}$ (II) ion.

\section{Experimental}

\section{Materials}

AN (Wako), PN (Wako), BuN (Tokyo Chemical), iBuN (Tokyo Chemical), VN (Tokyo Chemical), and 
BzN (Wako) were distilled twice after dehydration using 4A molecular sieves. In the case of $\mathrm{BzN}$, the distillation was performed under reduced pressure. The amount of water in the solvents was checked to be less than $5 \times 10^{-3} \mathrm{~mol} \mathrm{~kg}^{-1}$ by the Karl-Fisher titration method. Ethylenediamine (EN, Wako) was purified using a previously reported procedure. ${ }^{11,12}$

To prepare hydrated nickel(II) trifluoromethanesulfonate $\left(\mathrm{Ni}\left(\mathrm{H}_{2} \mathrm{O}\right)_{6}\left(\mathrm{CF}_{3} \mathrm{SO}_{3}\right)_{2}\right)$, an aqueous solution of trifluoromethanesulfonic acid was dropped into nickel(II) carbonate (Wako) suspended in water. The resulting solution was filtered and concentrated, and a green salt was then precipitated by cooling.

\section{Preparation of sample solutions}

An adequate amount of $\mathrm{Ni}\left(\mathrm{H}_{2} \mathrm{O}\right)_{6}\left(\mathrm{CF}_{3} \mathrm{SO}_{3}\right)_{2}$ was dissolved in distilled nitrile and the water contained was removed by refluxing in a modified Soxhlet extractor with activated $4 \mathrm{~A}$ molecular sieves. ${ }^{13}$ The reflux was repeated with freshly activated $4 \mathrm{~A}$ molecular sieves until the water concentration in the solution became negligible relative to the $\mathrm{Ni}$ (II) ion. The $\mathrm{Ni}$ (II) ion concentration of each nitrile solution was determined by EDTA titration and the values are summarized in Table 1. In order to prepare an aqueous solution of $\left[\mathrm{Ni}(\mathrm{en})_{3}\right]^{2+}$, $\mathrm{Ni}\left(\mathrm{H}_{2} \mathrm{O}\right)_{6}\left(\mathrm{CF}_{3} \mathrm{SO}_{3}\right)_{2}$ was dissolved in a mixed solvent of water and $\mathrm{EN}$ with the volume ratio of $1: 1$. Because the concentration of EN was $c a .17 \mathrm{~mol} \mathrm{~kg}^{-1}$ in this solution, the $\left[\mathrm{Ni}(\mathrm{en})_{3}\right]^{2+}$ complex was completely formed, based on its stability constant. ${ }^{14}$ An aqueous solution of $\mathrm{Ni}(\mathrm{II})$ ion was also prepared by dissolving $\mathrm{Ni}\left(\mathrm{H}_{2} \mathrm{O}\right)_{6}\left(\mathrm{CF}_{3} \mathrm{SO}_{3}\right)_{2}$ in doubly distilled water.

\section{EXAFS measurement and data analysis}

The sample solutions for EXAFS measurements were absorbed in porous glass disks which were sealed with polyethylene film in order to prevent any moisture ingress and evaporation of the solvent. X-Ray absorption spectra around the nickel $\mathrm{K}$ edge were measured using the BL6B station at the Photon Factory of the National Laboratory for High Energy Physics. ${ }^{15}$ The white synchrotron radiation was monochromatized by $\mathrm{Si}(111)$ double crystals which were detuned to $70 \%$ of the maximal intensity at $8.353 \mathrm{keV}$ in order to remove the higher-order reflection. The incident X-ray intensity and the transmitted intensity were simultaneously measured by the ionization chambers in lengths of 17 and $31 \mathrm{~cm}$, filled with $\mathrm{N}_{2}$ gas and with a 1:3 mixture of $\mathrm{Ar}$ and $\mathrm{N}_{2}$ gas, respectively.

The details of the EXAFS data analysis were described in previous publications. ${ }^{2,5,16}$ The background absorption $\left(\mu_{b}\right)$ and the smooth $\mathrm{K}$-shell absorption $\left(\mu_{0}\right)$ were estimated by fitting the Victoreen equation and a sixthorder polynomial function, respectively. The residuals by the subtraction of $\mu_{\mathrm{b}}$ and $\mu_{0}$ from observed absorbances were normalized by $\mu_{0}$, and the EXAFS oscillation function $\chi_{\text {obsd }}(k)$ was then obtained. The model function of EXAFS oscillation $\chi_{\text {calc }}(k)$ was given by the single-electron and single-scattering theory as ${ }^{17}$

$$
\begin{aligned}
\chi_{\text {calc }}(k)= & \Sigma_{\mathrm{j}}\left\{\frac{n_{\mathrm{j}}}{k r_{\mathrm{j}}^{2}}\right\} \exp \left(-2 \sigma_{\mathrm{j}}^{2} k^{2}-\frac{2 r_{\mathrm{j}}}{\lambda}\right) \times \\
& F_{\mathrm{j}}(\pi, k) \sin \left\{2 k r_{\mathrm{j}}-\alpha_{\mathrm{j}}(k)\right\}
\end{aligned}
$$

where $F_{\mathrm{j}}(\pi, k)$ and $\alpha_{\mathrm{j}}(k)$ are the back scattering amplitude from each of the $n_{\mathrm{j}}$ scatterers $\mathrm{j}$ at distance $r_{\mathrm{j}}$ from the $\mathrm{X}$-ray absorbing atom and the total phase shift, respectively. In this study, we have used the values for these parameters previously reported in the literature. ${ }^{18}$ $\sigma_{\mathrm{j}}$ and $\lambda$ are the Debye-Waller factor and the mean free path of a photoelectron, respectively. Because the structure of $\mathrm{Ni}\left(\mathrm{CH}_{3} \mathrm{CN}\right)_{6}\left(\mathrm{ClO}_{4}\right)_{2}$ was previously determined by $\mathrm{X}$-ray crystallography ${ }^{19}$, the solvation structures in nitriles except for AN were determined by referring to the AN solution as a structure standard. Only in the case of the aqueous solution of $\left[\mathrm{Ni}(\mathrm{en})_{3}\right]^{2+}$ was $\left[\mathrm{Ni}\left(\mathrm{H}_{2} \mathrm{O}\right)_{6}\right]^{2+}$ in water used as the standard. The values of $r_{\mathrm{j}}, \sigma_{\mathrm{j}}$, and $n_{\mathrm{j}}$ for the nickel(II) ion in the other nitriles and $\left[\mathrm{Ni}(\mathrm{en})_{3}\right]^{2+}$ in water were then optimized as variables. A curve fitting procedure for refinement of the structure parameters was applied to the Fourier filtered $k^{3} \chi_{\text {obsd }}(k)$ values so as to minimize the error-squares

\begin{tabular}{|c|c|c|c|c|c|}
\hline Solvent & Concentration $/ \mathrm{mol} \mathrm{kg}^{-1}$ & Interaction & $r^{\mathrm{b}} / \mathrm{pm}$ & $\sigma^{c} / p m$ & $n^{d}$ \\
\hline AN & 0.350 & $\mathbf{N i}-\mathbf{N}$ & $206.9 \pm 0.6$ & $7.0 \pm 0.1$ & $6^{e}$ \\
\hline PN & 0.380 & $\mathbf{N i}-\mathbf{N}$ & $206.9 \pm 0.6$ & $6.8 \pm 0.1$ & $5.9 \pm 0.2$ \\
\hline BuN & 0.422 & $\mathbf{N i}-\mathbf{N}$ & $206.8 \pm 0.6$ & $7.0 \pm 0.1$ & $6.0 \pm 0.2$ \\
\hline $\mathrm{iBuN}$ & 0.383 & $\mathbf{N i}-\mathbf{N}$ & $206.8 \pm 0.6$ & $7.0 \pm 0.1$ & $6.0 \pm 0.2$ \\
\hline VN & 0.424 & $\mathrm{Ni}-\mathbf{N}$ & $206.8 \pm 0.6$ & $7.0 \pm 0.1$ & $6.0 \pm 0.2$ \\
\hline BzN & 0.228 & $\mathrm{Ni}-\mathbf{N}$ & $206.5 \pm 0.7$ & $6.7 \pm 0.1$ & $6.0 \pm 0.2$ \\
\hline Water & 0.312 & $\mathrm{Ni}-\mathrm{O}$ & $205.0 \pm 0.6$ & $6.5 \pm 0.1$ & $6^{e}$ \\
\hline Water $+E^{f}$ & 0.658 & $\mathbf{N i}-\mathbf{N}$ & $212.1 \pm 0.6$ & $6.7 \pm 0.1$ & $5.9 \pm 0.2$ \\
\hline
\end{tabular}

Table 1 Structure parameters around nickel(II) ion in nitriles ${ }^{\mathrm{a}}$

a. $E_{0}=8352.5 \pm 0.2 \mathrm{eV}$ and $\lambda=662 \pm 14 \mathrm{pm}$ for nitrile solutions and $E_{0}=8352.3 \pm 0.2 \mathrm{eV}$ and $\lambda=579 \pm 7 \mathrm{pm}$ for aqueous solutions. Errors are the standard deviations in the least-squares calculation. b. The bond length between the Ni(II) ion and the coordinating donor atom. c. The Debye-Waller factor. d. The coordination number. e. Fixed during a least-squares calculation. f. The values for the $\left[\mathrm{Ni}(\mathrm{en})_{3}\right]^{2+}$ complex in a mixed solvent of water and EN with the volume ratio of $1: 1$. 


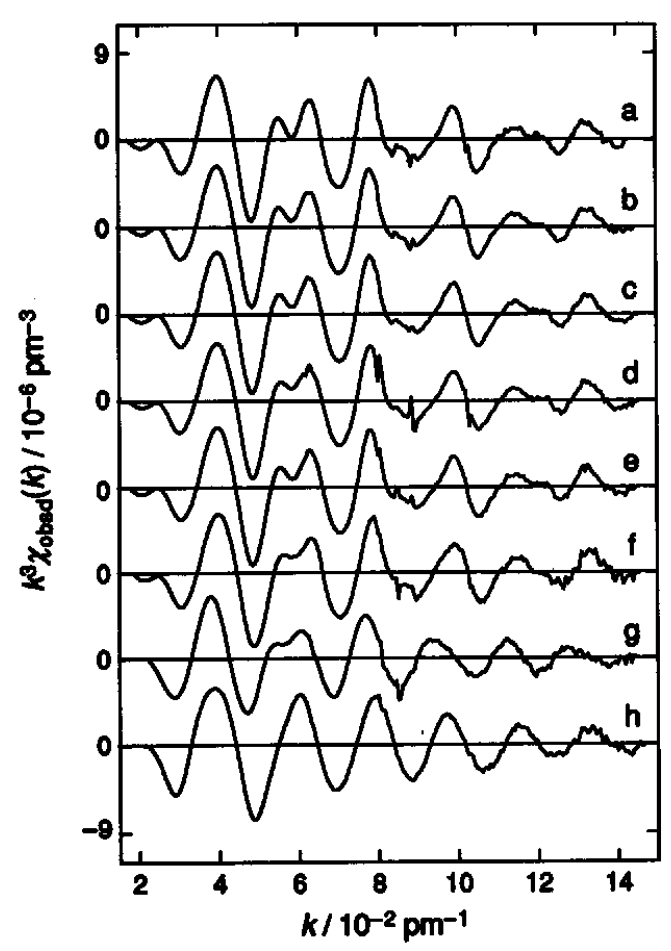

Fig. 1 The $k^{3}$-weighted EXAFS oscillations for nitrilesolvated Ni(II) ion in AN (a), PN (b), BuN (c), iBuN (d), VN (e), and $\mathrm{BzN}(\mathrm{f})$, and for $\left[\mathrm{Ni}(\mathrm{en})_{3}\right]^{2+}(\mathrm{g})$ and $\left[\mathrm{Ni}\left(\mathrm{H}_{2} \mathrm{O}\right)_{6}\right]^{2+}(\mathrm{h})$ in water.

sum, $\Sigma\left\{k^{3} \chi_{\text {obsd }}(k)-k^{3} \chi_{\text {calc }}(k)\right\}^{2}$. The obtained structure parameters are summarized in Table 1.

\section{Results and Discussion}

\section{Solvation structures in nitriles}

The observed EXAFS oscillations weighted by $k^{3}$ (Fig. 1) show complex structures and it is expected that there are more than one interaction shell around the Ni(II) ion. The $k^{3} \chi_{\text {obsd }}(k)$ values in the $k$ range of (214.5) $\times 10^{-2} \mathrm{pm}^{-1}$ were Fourier-transformed; Fig. 2 shows the Fourier transform magnitudes, with the phase factor being uncorrected. In addition to the main peak observed around $180 \mathrm{pm}$, which is attributed to the $\mathrm{Ni}-\mathrm{N}$ bonding interaction, the longer non-bonding interactions appear in the $r$ range of $200-450 \mathrm{pm}$. These peaks can be assigned to the interactions between the $\mathrm{Ni}(\mathrm{II})$ ion and the carbon atoms of cyano and alkyl or aryl groups. It should be noted, however, that the peak intensity around $250 \mathrm{pm}$ is somewhat higher than those observed for $\left[\mathrm{Ni}(\mathrm{en})_{3}\right]^{2+}$ (Fig. 2(g)), pyridine derivatives ${ }^{8}$, and the other metal(II) ions in EN. ${ }^{5}$ This is characteristic for the linear orientation of $\mathrm{Ni}, \mathrm{N}$, and $\mathrm{C}$ atoms; the higher intensity can be ascribed to the multiple scatterings. Similar intense peaks of $\mathrm{M}$...C interactions are observed in the Fourier transforms of $\mathrm{Mn}(\mathrm{II})^{4}, \mathrm{Cu}(\mathrm{I})^{6}, \mathrm{Cu}(\mathrm{II})^{6}$, $\operatorname{Au}(\mathrm{I})^{20}$, and $\mathrm{Ag}(\mathrm{I})^{21}$ ions in $\mathrm{AN}$. In this study, we have

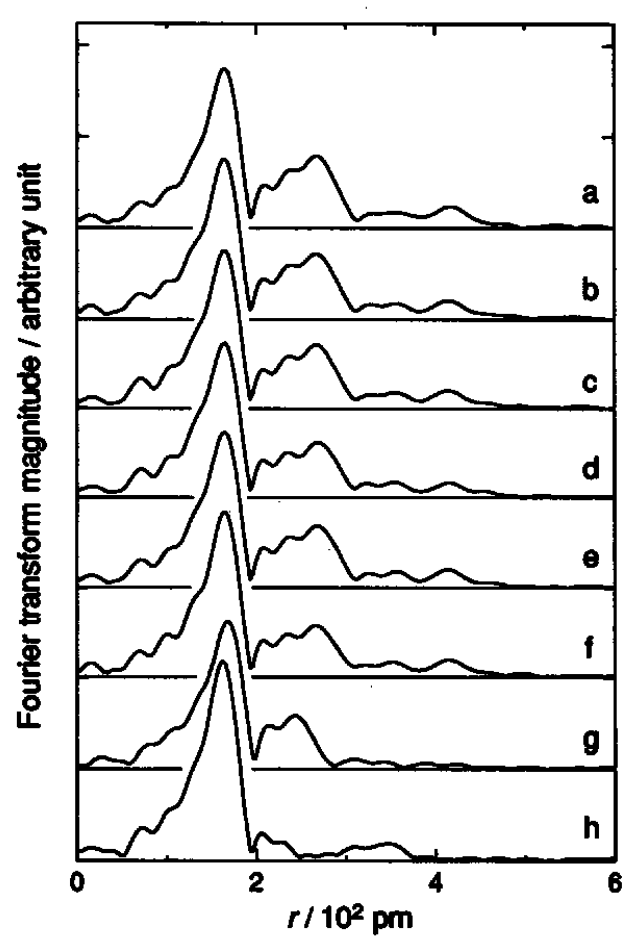

Fig. 2 Fourier transform magnitudes for nitrile-solvated Ni(II) ion in AN (a), PN (b), BuN (c), iBuN (d), VN (e), and $\mathrm{BzN}(\mathrm{f})$, and for $\left[\mathrm{Ni}(\mathrm{en})_{3}\right]^{2+}(\mathrm{g})$ and $\left[\mathrm{Ni}\left(\mathrm{H}_{2} \mathrm{O}\right)_{6}\right]^{2+}(\mathrm{h})$ in water.

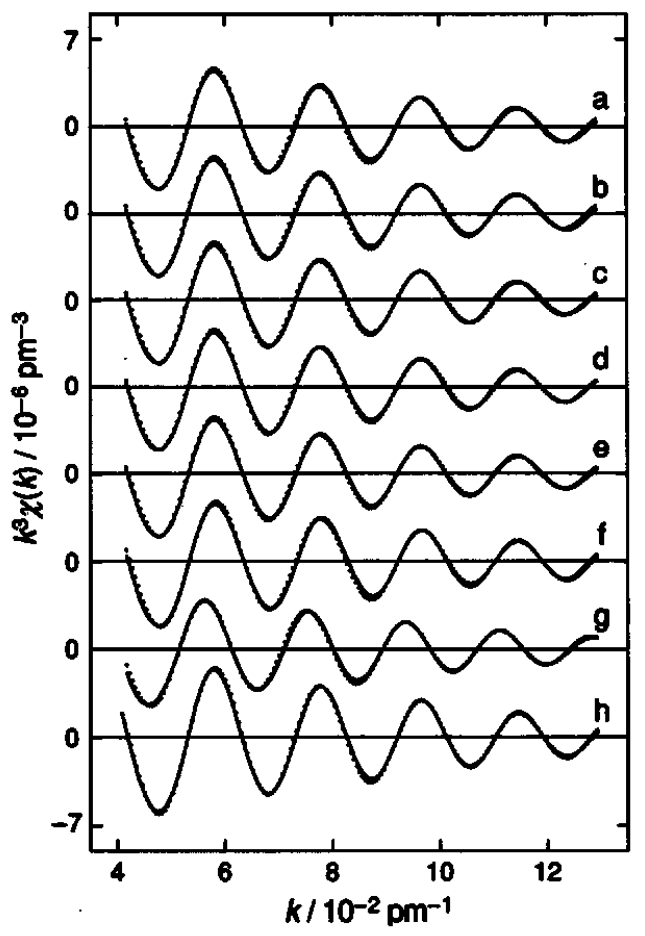

Fig. 3 The Fourier filtered $k^{3} \chi(k)$ values (dots) and the $k^{3} \chi_{\text {calc }}(k)$ values (solid line) depicted using the structure parameters given in Table 1 for nitrile-solvated Ni(II) ion in AN (a), PN (b), BuN (c), iBuN (d), VN (e), and BzN (f), and for $\left[\mathrm{Ni}(\mathrm{en})_{3}\right]^{2+}(\mathrm{g})$ and $\left[\mathrm{Ni}\left(\mathrm{H}_{2} \mathrm{O}\right)_{6}\right]^{2+}(\mathrm{h})$ in water. 
focused on the local structure in the neighborhood of the $\mathrm{Ni}(\mathrm{II})$ center and only the main peaks were then analyzed. In Fig. 3 are depicted the Fourier filtered $k^{3} \chi(k)$ values and the theoretical $k^{3} \chi(k)$ curves calculated using Eq. (1) with the obtained structure parameters in Table 1 . The calculated curves are in excellent agreement with the values of Fourier filtered $k^{3} \chi(k)$ in all $k$ regions used in the least-squares calculation $\left(4 \leq k / 10^{-2} \mathrm{pm} \leq 13\right)$.

The fact that the coordination number of the $\mathrm{Ni}$ (II) ion in all nitriles is 6 supports that six nitrile molecules octahedrally coordinate to the Ni(II) ion. The structure is consistent with the expectation from UV/vis absorption spectra. ${ }^{22}$ The solvation geometry around the $\mathrm{Ni}(\mathrm{II})$ ion is not influenced by the increase in size of a substituent of the cyano group due to the cylindrical form of the nitrile molecules. The values of $r$ in all nitriles are $207 \pm 1 \mathrm{pm}$, and thus not only the coordination number, but also the Ni-N bond length is not changed by the size of the substituent. The enthalpies for protonation of nitriles in the gas phase have been compiled and the enthalpy values are increased in the order of $\mathrm{AN}<$ PN $<$ BuN $<$ iBuN $<$ VN $<$ BzN. $^{23}$ These values are regarded as parallel with the $\sigma$-donating ability of the nitrogen atom and the ability to the hard proton is then largest for $\mathrm{BzN}$. Interestingly, the $\mathrm{Ni}-\mathrm{N}$ bond length does not seem to be sensitive to the difference in $\sigma$ donating ability. The bond distance is rather decided by the kind of donating atoms as discussed below.

\section{Bond lengths between $\mathrm{Ni}(\mathrm{II})$ ion and donor atoms}

We have determined the structure parameters around the nickel(II) center in the $\left[\mathrm{Ni}(\mathrm{en})_{3}\right]^{2+}$ complex in this study (see Table 1). Though the $r$ value of the Ni-N bond for $\left[\mathrm{Ni}(\mathrm{en})_{3}\right]^{2+}$ is slightly different from the corresponding value determined by the $\mathrm{X}$-ray diffraction $\operatorname{method}^{24}$, it is consistent with the values in the aqueous and crystalline phases. ${ }^{25,26}$ Because the value of $r$ in the aqueous solution is in accordance with the corresponding values in the crystal, the outer-sphere hydration around the $\left[\mathrm{Ni}(\mathrm{en})_{3}\right]^{2+}$ complex does not seem to affect the structure parameters. Previously, the $\mathrm{Ni}-\mathrm{N}$ bond length in 1,3-propanediamine (TN) has been reported as $214 \mathrm{pm}^{7}$ The bond lengths in $\left[\mathrm{Ni}(\mathrm{en})_{3}\right]^{2+}$ and $\left[\mathrm{Ni}(\mathrm{tn})_{3}\right]^{2+}$ are longer by 5 and $7 \mathrm{pm}$ than that in nitriles. Although the protonation constants of EN and TN are higher by over ten orders than those of nitriles ${ }^{23}$, the $\mathrm{Ni}-\mathrm{N}$ bond is rather longer than that in nitriles. EN and TN have $\mathrm{sp}^{3}$ nitrogen donor atoms, whereas that in nitriles is an spnitrogen. The electron density distribution of the lone pair orbital for the former, which has more p-like character, should be more expanded compared to the latter. Such lone-pair orbitals of the donating atom make the $\mathrm{Ni}(\mathrm{II})$ ion far away from the nitrogen atom. In 3- and 4-methylpyridine, the $\mathrm{Ni}-\mathrm{N}$ bond lengths are reported as 210 and $211 \mathrm{pm}$, respectively ${ }^{8}$, and the bond distances with an $\mathrm{sp}^{2}$-nitrogen are observed between those for nitrile-solvated $\mathrm{Ni}$ (II) complexes and for aliphatic amine complexes $\left(\left[\mathrm{Ni}(\mathrm{en})_{3}\right]^{2+}\right.$ and $\left.\left[\mathrm{Ni}(\mathrm{tn})_{3}\right]^{2+}\right)$. Thus, the Ni-N bond length is affected by the orbital character of the donating atoms.

It is noted that the observed $\mathrm{Ni}-\mathrm{N}$ bond length of the $\left[\mathrm{Ni}(\mathrm{en})_{3}\right]^{2+}$ complex in the aqueous solution is shorter by $2 \mathrm{pm}$ than that of $\left[\mathrm{Ni}(\mathrm{tn})_{3}\right]^{2+}$ in TN. Based on the review of structures for diamine complexes, where the relationship between the $\mathrm{M}-\mathrm{N}$ distance and the $\mathrm{M}-\mathrm{N}-\mathrm{C}$ angle of the chelate ring has been shown, the unfavorable chelate-ring strain is expected for the 6-membered TN ring around the $\mathrm{Ni}(\mathrm{II})$ ion. ${ }^{12}$ The 6-membered ring of TN seems to be too large for the $\mathrm{Ni}$ (II) ion and thus the $\mathrm{Ni}-\mathrm{N}$ bond in the TN complex is thought to become longer than that in the EN complex.

The $\mathrm{Ni}-\mathrm{O}$ bond length of the hexaaqua nickel(II) ion in water is determined to be $205.0 \pm 0.6 \mathrm{pm}$, which is in agreement with the values previously reported within the experimental uncertainties. ${ }^{1-3,8,9}$ In contrast to the case of the nitrogen donating ligands, the $\mathrm{Ni}-\mathrm{O}$ bond lengths in $N, N$-dimethylformamide (204 pm) and $N, N$-dimethylacetamide $(205 \mathrm{pm})$, which have an $\mathrm{sp}^{2}$-oxygen as the donating atom, are not different from that in water with an sp ${ }^{3}$-oxygen. ${ }^{9}$ These results suggest that the electron density distribution of the lone-pair orbitals for the donor oxygen atoms is not so changed by its hybridization environments, i.e., the oxygen atom is harder than nitrogen.

\section{Reconsideration of nitrile exchange on $\mathrm{Ni}(\mathrm{II})$ ion}

Previously, nitrile exchange reactions on the Ni(II) ion in AN, PN, BuN, iBuN, VN, and BzN have been studied and, on the basis of their kinetic parameters, the reaction mechanisms have been regarded as the same dissociative interchange in all nitriles. ${ }^{22}$ The present work indicates that the solvation structure of the Ni(II) ion in the six nitriles is 6-coordinate octahedral and that the Ni-N bond lengths are virtually the same. These findings provide very useful knowledge of the solvation structures in the ground state for the solvent exchange reaction. Therefore, by attempting the reconsideration of reported kinetic parameters (activation enthalpy $\left(\Delta H^{\ddagger}\right)$ and activation entropy $\left(\Delta S^{\ddagger}\right)$ ), we can obtain further information about the reaction mechanism of the nitrile exchange on the nickel(II) ion.

The facts that the donor number is nearly the same for all nitriles ${ }^{27}$ and that the ligand field splittings $10 D q$ and Racah's $B$ values are not varied for all nitrile-solvated nickel(II) complexes $^{28}$ correspond to the same solvation structure of the Ni(II) ion in all nitriles. According to the previous report ${ }^{22}$, the value of $\Delta H^{\ddagger} / \mathrm{kJ} \mathrm{mol}^{-1}$ for the nitrile exchange is increased in the order of $\mathrm{AN}(41.4)<$ $\mathrm{PN}(42.0)<\mathrm{BuN}(43.3) \approx \mathrm{iBuN}(43.3)<\mathrm{VN}(47.1)<$ BzN(51.6). Taking into consideration the same solvation structure in the ground state, this finding suggests that the reaction mechanism becomes more dissociative in the above order. Such a gradual change in the reaction mechanism also appears in the $\Delta S^{\ddagger}$ values, which increase in response to the $\Delta \boldsymbol{H}^{\ddagger}$. For the more dissociative transition state, the more distant nitrile molecules gain the larger entropy due to the increase in intramolecular freedom of the exchanging nitrile 
molecules. On the contrary, it is somewhat interesting that many values of $\Delta S^{\ddagger}$ in nitriles are negative, which is the opposite to that expected based on the dissociative interchange mechanisms. ${ }^{29}$ According to the recently reported structure of the transition state for the water exchange reaction on the nickel(II) ion, the five remaining water molecules are contracted for the dissociative mode of activation. ${ }^{30}$ Such a contraction may then contribute to negative $\Delta S^{\ddagger}$ and is effective for the exchange of the solvent molecules with an alkyl chain, such as nitriles which have large intramolecular freedom in the free form.

This work was supported by Grants-in-Aid for Scientific Research (Nos. 07504003 and 07454199) from the Ministry of Education, Science, Sports, and Culture of Japan. The EXAFS measurements were performed under the approval of the Photon Factory Program Advisory Committee (Proposal No. 92G179).

\section{References}

1. (a) H. Ohtaki and T. Radnai, Chem. Rev., 93, 1157 (1993). (b) Y. Marcus, Chem. Rev., 88, 1475 (1988).

2. Y. Inada, K. Sugimoto, K. Ozutsumi and S. Funahashi, Inorg. Chem., 33, 1875 (1994).

3. K. Ozutsumi, Y. Abe, R. Takahashi and S. Ishiguro, $J$. Phys. Chem., 98, 9894 (1994).

4. Y. Inada, T. Sugata, K. Ozutsumi and S. Funahashi, submitted.

5. Y. Inada, K. Ozutsumi, S. Funahashi, S. Soyama, T. Kawashima and M. Tanaka, Inorg. Chem., 32, 3010 (1993).

6. I. Persson, J. E. P.-Hahn and K. O. Hodgson, Inorg. Chem., 32, 2497 (1993).

7. S. Aizawa, S. Iida, K. Matsuda and S. Funahashi, Bull. Chem. Soc. Jpn., 70, in press (1997).

8. M. Kurihara, K. Ozutsumi and T. Kawashima, J. Sol. Chem., 24, 719 (1995).

9. K. Ozutsumi, M. Koide, H. Suzuki and S. Ishiguro, $J$. Phys. Chem., 97, 500 (1993).

10. R. D. Shannon, Acta Crystallogr., A32, 751 (1976).

11. S. Soyama, M. Ishii, S. Funahashi and M. Tanaka, Inorg. Chem., 31, 536 (1992).

12. S. Aizawa, K. Matsuda, T. Tajima, M. Maeda, T. Sugata and S. Funahashi, Inorg. Chem., 34, 2042 (1995).

13. S. Funahashi, "High Pressure Liquids and Solutions", Ed. Y. Taniguchi, M. Senoo and K. Hara, Elsevier, New York, 1994.

14. (a) K. Morinaga, Bull. Chem. Soc. Jpn., 29, 793 (1956). (b) P. L. Peczok and J. Bjerrum, Acta Chem. Scand., 11, 1419 (1957). (c) M. Ciampolini, P. Paoletti and L. Sacconi, J. Chem. Soc., 1953, 4553.

15. M. Nomura, A. Koyama and M. Sakurai, "KEK Report 91-1", National Laboratory for High Energy Physics, Tsukuba, 1991.
16. H. Ohtaki, Y. Inada, S. Funahashi, M. Tabata, K. Ozutsumi and K. Nakajima, J. Chem. Soc., Chem. Commun., 1994, 1023.

17. (a) D. E. Sayers, E. A. Stern and F. W. Lytle, Phys. Rev. Lett., 27, 1204 (1971). (b) E. A. Stern, Phys. Rev. B, 10, 3027 (1974). (c) F. W. Lytle, D. E. Sayers and E. A. Stern, Phys. Rev. B, 11, 4825 (1975). (d) E. A. Stern, D. E. Sayers and F. W. Lytle, Phys. Rev. B, 11, 4836 (1975). (e) B. Lengeler and P. Eisenberger, Phys. Rev. B, 21, 4507 (1980). (f) P. A. Lee, P. H. Citrin, P. Eisenberger and B. M. Kincaid, Rev. Mod. Phys., 53, 769 (1981).

18. B. K. Teo and P. A. Lee, J. Am. Chem. Soc., 101, 2815 (1979).

19. R. Bougon, P. Charpin, K. O. Christe, J. Isabey, M. Lance, M. Nierlich, J. Vigner and W. W. Wilson, lnorg. Chem., 27, 1389 (1988).

20. S. Ahrland, K. Nilsson, I. Persson, A. Yuchi and J. E. P.Hahn, Inorg. Chem., 28, 1833 (1989).

21. (a) T. Yamaguchi, H. Wakita and M. Nomura, J. Chem. Soc., Chem. Commun., 1988, 433. (b) Y. Tsutsui, K. Sugimoto, H. Wasada, Y. Inada and S. Funahashi, $J$. Phys. Chem., A, 101, 2900 (1997).

22. M. Ishii, S. Funahashi, K. Ishihara and M. Tanaka, Bull. Chem. Soc. Jpn., 62, 1852 (1989).

23. S. G. Lias, J. F. Liebman and R. D. Levin, J. Phys. Chem. Ref. Data, 13, 695 (1984).

24. T. Fujita and H. Ohtaki, Bull. Chem. Soc. Jpn., 55, 455 (1982).

25. M. Sano, T. Maruo and H. Yamatera, Bull. Chem. Soc. Jpn., 57, 2757 (1984).

26. (a) M. U.-Hague, C. N. Caughlan and K. Emerson, Inorg. Chem., 9, 2421 (1971). (b) R. E. Cramer, W. van Doorne and J. T. Huneke, Inorg. Chem., 15, 529 (1976). (c) R. E. Cramer and J. T. Huneke, Inorg. Chem., 17, 365 (1978). (d) G. B. Jameson, R. Schneider, E. Dubler and H. R. Oswald, Acta Crystallogr., B38, 3016 (1982).

27. (a) V. Gutmann, "The Donor-Acceptor Approach to Molecular Interactions", Plenum Press, New York, 1978. (b) J. A. Riddick, W. B. Bunger and T. K. Sakano, "Organic Solvents: Physical Properties and Methods of Purification", John Wiley \& Sons, New York, 1986. The donor numbers of $\mathrm{AN}, \mathrm{PN}, \mathrm{BuN}, \mathrm{BBN}$, and $\mathrm{BzN}$ are $14.1,16.1,16.6,15.4$, and 11.9 , respectively.

28. The values of $10 \mathrm{Dq} / 10^{3} \mathrm{~cm}^{-1}$ and $B / \mathrm{cm}^{-1}$ were calculated from the spectra given in reference 22 as follows: 12.8 and 420 for $\mathrm{AN}, 12.7$ and 380 for PN, 12.7 and 370 for $\mathrm{BuN}$, 12.6 and 337 for $\mathrm{iBuN}, 12.7$ and 360 for $\mathrm{VN}$, and 12.7 and 330 for $\mathrm{BzN}$, respectively.

29. (a) A. E. Merbach, Pure Appl. Chem., 54, 1479 (1982). (b) A. E. Merbach, Pure Appl. Chem., 59, 161 (1987). (c) S. F. Lincoln and A. E. Merbach, Adv. Inorg. Chem., 42, 1 (1995).

30. F. P. Rotzinger, J. Am. Chem. Soc., 118, 6760 (1996).

(Received December 27, 1996) (Accepted March 6, 1997) 